\title{
Ewe whole body composition predicted in vivo by real-time ultrasonography and image analysis
}

\author{
S.R. Silva ${ }^{\mathrm{a}, *}$ J. Afonso $^{\mathrm{b}}$, C.M. Guedes $^{\mathrm{a}}$, M.J. Gomes ${ }^{\mathrm{a}}$, V.A. Santos ${ }^{\mathrm{a}}$, J.M.T. Azevedo ${ }^{\mathrm{a}}$, \\ A. Dias-da-Silva ${ }^{a}$ \\ a CECAV, Universidade de Trás-os-Montes e Alto Douro, 5001-801 Vila Real, Portugal \\ b CIISA, FMV, ULisboa, Avenida da Universidade Técnica, 1300-477 Lisboa, Portugal
}

\section{A R T I C L E I N F O}

\section{Article history:}

Received 26 June 2015

Received in revised form 12 January 2016

Accepted 29 January 2016

Available online 1 February 2016

\section{Keywords:}

Mature ewes

Chemical body composition

Real-time ultrasound

\begin{abstract}
A B S T R A C T
The relationship between ultrasound measurements and the empty body chemical composition of mature ewes was studied in two breeds. The breeds were a milk-producing breed Churra da Terra Quente-CTQ ( $n=33$; live weight $42.0 \pm 7.3 \mathrm{~kg}$, mean $\pm \mathrm{SD}$ ), and a meat breed Ile de France-IF ( $n=23$; live weight $60.7 \pm 9.1 \mathrm{~kg}$, mean $\pm \mathrm{SD}$ ). Fat and muscle depths were measured in the live animals by real-time ultrasound scanning (RTU; $7.5 \mathrm{MHz}$ probe) over the 13th thoracic, and between the 3rd and 4th lumbar vertebrae, and total tissue depth over the 11th rib. Following slaughter, the carcass and non-carcass components of the empty body were combined and subjected to chemical analysis and assessment of energy value. Data obtained by RTU after image analysis was used to develop simple and multiple regression models for each breed. The traits most accurately estimated from single RTU measurements were the absolute values for fat content and energy value of the empty body. The respective coefficients of determination $\left(R^{2}\right)$ for IF and CTQ ewes using subcutaneous fat depth over the 13th thoracic vertebra were 0.768 and 0.908 for fat, 0.821 and 0.900 for energy; and for measurements between the 3rd and 4th lumbar vertebrae were 0.845 and 0.911 for fat, 0.852 and 0.906 for energy. All these coefficients were significant $(P<0.01)$. The best prediction models included one to three RTU measurements and were better for CTQ ewes, where adjusted $R^{2}$ values ranged from $0.923(P<0.001)$ for water to $0.969(P<0.001)$ for protein, than for IF ewes, where the range was $0.394(P<0.01)$ for protein to $0.940(P<0.001)$ for fat. The results revealed good estimates of the fat and energy content of the empty body of both breeds and also good estimates of protein content for CTQ ewes, but poor estimates of protein content for IF ewes, with the best prediction models for each body component being different from each breed. Consequently, it is concluded that predictive models that are specific to the breed and circumstances of the study in which they are to be used will have to be established to have a practical application.
\end{abstract}

(c) 2016 Elsevier B.V. All rights reserved.

\section{Introduction}

The knowledge of chemical body composition is fundamental to study the effect of nutritional and genetic factors on livestock production. Body composition studies in meat animals have focused primarily on those changes that occur during the growth of the animal up to "market weight", but also on changes that occur during pregnancy and lactation (Mitchell, 2007). Even today, dissection and chemical analysis represent the standard for body composition determination of farm animals. However, such techniques raise several problems (e.g., ethical problems, the impossibility of

\footnotetext{
* Corresponding author. Fax: +351 259350482

E-mail address: ssilva@utad.pt (S.R. Silva).
}

within animal comparisons and need of large numbers of animals, very intensive labor and high cost). To overcome these constraints several in vivo image methodologies have been proposed to get accurate estimates of chemical body composition, such as computer tomography (CT), magnetic resonance imaging, dual-energy X-ray absorptiometry or real-time ultrasound (RTU). These techniques have been reviewed by several authors (Silva and Cadavez, 2012; Scholz et al., 2015). The RTU scanning is already largely used in animal production and is considerably less expensive than other imaging techniques. Concerning the estimation of dissectible carcass components, many studies have been made based on ultrasonic measurements and the effectiveness of regression models for prediction of carcass composition is now well established, particularly for growing animals (Ripoll et al., 2009; Grill et al., 2015). Concerning the prediction of chemical body composition the data 
available are scarcer, although some results have already been available for sows (King et al., 1986), lactating cows (Wright and Russel, 1984) and sheep (Leymaster et al., 1985). Besides, there is not much information about the comparison of prediction models obtained for different breeds kept in similar conditions, using ultrasonic measurements. The present study aims to estimate in vivo whole empty body chemical composition for ewes of Churra da Terra Quente (CTQ) and Ile de France (IF) breeds using RTU and image analysis.

\section{Materials and methods}

\subsection{Animals}

Experimental animals were cared and handled in accordance with the guidelines of EU directive number 2010/63/EU and all RTU examinations were done by an experienced technician with accreditation by FELASA Category $C$. The experimental animals consisted of 56 mature, non-pregnant and non-lactating ewes of the native milk producing breed CTQ $(n=33$; live weight $42.0 \pm 7.3 \mathrm{~kg}$, mean $\pm \mathrm{SD}$ ), and the meat producing breed IF ( $n=23$; live weight $60.7 \pm 9.1 \mathrm{~kg}$, mean $\pm \mathrm{SD}$ ).

\subsection{Ultrasound image capture and analysis}

Before ultrasound scanning, the animals were shorn, deprived of food for $24 \mathrm{~h}$ and weighed. The wool at each scanning location was clipped close to the skin, and a gel was used as a coupling medium. The animals were scanned with an Aloka SSD 500 V scanner (Tokyo, Japan) using a linear probe of $7.5 \mathrm{MHz}$ (UST-5512U-7.5, $38 \mathrm{~mm}$, Tokyo, Japan). The probe was placed perpendicular to the backbone, over the 13th thoracic vertebra and between the 3rd and the 4th lumbar vertebrae. Subcutaneous fat depth (SF) was measured at both locations (SF13 and SF34, respectively), as well as the longissimus thoracis et lumborum muscle depth (MD13 and MD34, respectively). Also, a tissue depth measurement (TDtho) was also obtained over the 11 th rib, $16 \mathrm{~cm}$ from the dorsal midline. Images were captured on a digital video camera (DCR-HC96E, Sony, Tokyo, Japan). Then, images from each site were saved in JPEG image format, and the measurements above mentioned were obtained by image analysis with ImageJ software.

\subsection{Slaughter procedure, samples collection, and chemical analysis}

After slaughtering the fore and hind limbs (feet) were separated at the radio-carpal and tarso-metatarsal joints, respectively. The pelt, head, and all the internal organs were removed and individually weighed. The alimentary tract was weighed full, and then emptied and reweighed. All non-carcass body components, including the pelt (which will be subsequently referred to as offal), were then combined and stored in plastic bags at $-20^{\circ} \mathrm{C}$ until grinding. The carcass was stored at $4{ }^{\circ} \mathrm{C}$ for 24 hours, reweighed and then split down the vertebral column with a band saw. The left half of the carcass was then stored in plastic bags at $-20^{\circ} \mathrm{C}$. Frozen carcasses and offal were cut into small pieces by an electric band saw and immediately ground in a mincer (Retsch SM 200, Haan, Germany) with a sieve plate having $8 \mathrm{~mm}$ diameter holes. The mixtures were then ground through another sieve plate with $4 \mathrm{~mm}$ diameter holes. Then the mixtures (carcass and offal) were homogenized in an industrial mixer (Stef, Rimini, Italy). For carcass and offal mixtures four random samples of approximately $300 \mathrm{~g}$ were obtained, placed in a sealed plastic box and stored at $-20^{\circ} \mathrm{C}$ for later chemical analysis.

Samples were analyzed in duplicate for moisture, ash, crude protein $(\mathrm{N} \times 6.25)$ and fat according to AOAC (1990). The energy value was determined by adiabatic bomb calorimetry (Parr 1241 calorimeter, Moline, IL). Carcass and offal composition ( $\mathrm{kg}$ ) were calculated from the respective weights and chemical composition. The weights of the empty body chemical components were calculated as the sum of carcass and offal components.

\subsection{Statistical analysis}

The chemical composition components and RTU measurements for both breeds were analyzed by ANOVA and mean differences were performed using Fisher LSD test with a significance level of $P<0.05$. To assess the accuracy of empty body chemical composition estimated by RTU simple regression equations were obtained. Also multiple regression analyzes were performed to determine which combinations of RTU measurements and LW best predicted empty body chemical composition and energy value. For both simple and multiple regressions the best fitting was evaluated by the coefficient of determination $\left(R^{2}\right)$ and residual standard of deviations (RSD). All statistical analysis was performed by JMP (Version 5.01; SAS Institute Inc., Cary, NC, USA).

\section{Results}

Churra da Terra Quente ewes showed significantly $(P<0.05)$ lower EBW (34.3vs. $50.8 \mathrm{~kg}$ ) and empty body content of water (17.8 $v s .28 .6 \mathrm{~kg})$, ash (1.34 vs. $2.44 \mathrm{~kg}$ ) and protein ( $5.51 v s .9 .33 \mathrm{~kg}$ ) than IF ewes (Table 1). The absolute empty body content of fat (8.66 vs. $10.5 \mathrm{~kg}$ ) and energy value (466 vs. $628 \mathrm{MJ}$ ) were also considerably lower in CTQ ewes, but the differences between the two breeds were not statistically significant $(P>0.05)$, due to the high $C V$ of the data. It must be pointed out that, concerning fat, protein and energy value, CV values were larger for CTQ ewes than for IF ewes. When the components were expressed as proportions of EBW (Table 1), all differences became not significant $(P>0.05)$, again with the high $\mathrm{CV}$ of the data playing an important role. For instance in the case of fat proportion, CTQ ewes show considerably higher fat proportion than IF ewes ( 252 vs. $202 \mathrm{~g} / \mathrm{kg}$ ), despite the lack of statistical significance. Expressing the different body components as proportions reduced the EBW effect on the breed comparisons and, with the exception of protein in Ile de France ewes, resulted in much lower $\mathrm{CV}$ values.

When comparing the RTU measurements at the thoracic and lumbar locations within a breed, the results showed no significant differences $(P>0.05$; Table 1$)$ both for subcutaneous fat depth and for muscle depth. There was no significant effect of breed on SF13, SF34 or TDtho. However, muscle depth at both sites (MD13 and MD34) was nearly $50 \%$ greater in IF than in CTQ ewes $(P<0.05)$. Both breeds showed considerable variation for all the RTU measurements obtained, and it can be pointed out that, except of TDtho (for which IF ewes showed higher CV), the coefficients of variation for CTQ ewes were much higher than those for IF ewes.

Considering the amount of variation explained by RTU measurements for total empty body components (Table 2), there was a tendency for better accuracy (based on $R^{2}$ ) of estimates in the case of CTQ ewes. Fat was clearly the body component more accurately estimated using RTU measurements. This is particularly true for CTQ ewes, using SF13, SF34 and even TDtho, which explained, respectively, $90.8,91.1$ and $85.1 \%$ of the variation in total fat content, and $78.3,81.1$ and $72.2 \%$ of the variation in fat proportion (Table 2). For IF ewes fat was also the better-predicted body component, but with less accuracy than for CTQ ewes and with MD13 and MD34 RTU measurements becoming almost as good estimators of fat content as SF13, SF34, and TDtho (Table 2). Still, RTU measurements of fat depth provided the best estimates, with SF13 and SF34 explaining, respectively, 76.8 and $84.5 \%$ of the variation 
Table 1

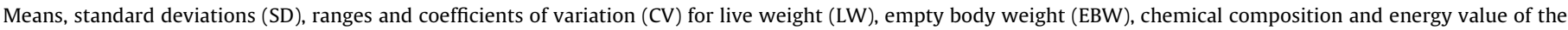
empty body and in vivo real-time ultrasonic (RTU) measurements ${ }^{\dagger}$ of Churra da Terra Quente (CTQ) and Ile de France (IF) ewes.

\begin{tabular}{|c|c|c|c|c|c|c|c|c|}
\hline & \multicolumn{4}{|l|}{ CTQ } & \multicolumn{4}{|l|}{ IF } \\
\hline & Mean & SD & Range & $\mathrm{CV}$ & Mean & SD & Range & $\mathrm{CV}$ \\
\hline LW, kg & $42.0 \mathrm{a}$ & 7.28 & $30.9-60.4$ & 17.32 & $60.7 b$ & 9.10 & $47.0-79.0$ & 14.98 \\
\hline EBW, kg & $34.3 a$ & 7.50 & $22.6-54.2$ & 21.88 & $50.8 \mathrm{~b}$ & 6.85 & $40.48-63.76$ & 13.48 \\
\hline \multicolumn{9}{|l|}{ Empty body } \\
\hline Water, kg & $17.8 \mathrm{a}$ & 2.89 & $12.7-26.1$ & 16.27 & $28.6 b$ & 2.97 & $23.3-33.6$ & 10.38 \\
\hline Ash, kg & $1.34 a$ & 0.19 & $0.96-1.81$ & 14.32 & $2.44 \mathrm{~b}$ & 0.49 & $1.80-3.31$ & 20.04 \\
\hline Fat, kg & $8.66 a$ & 3.29 & $4.29-17.9$ & 38.20 & $10.5 a$ & 3.28 & $4.31-15.9$ & 31.28 \\
\hline Protein, kg & $5.51 \mathrm{a}$ & 0.95 & $3.76-7.95$ & 17.26 & $9.33 \mathrm{~b}$ & 1.02 & $7.45-12.0$ & 10.95 \\
\hline Energy value, MJ & $465.8 \mathrm{a}$ & 148.3 & $266.9-889.4$ & 31.84 & $627.8 \mathrm{a}$ & 141.7 & $375.9-887.7$ & 22.60 \\
\hline \multicolumn{9}{|c|}{ Proportions of empty body } \\
\hline Water, g/kg & $540.4 a$ & 37.6 & $485.0-611.7$ & 6.96 & $565.1 \mathrm{a}$ & 29.5 & $516.6-633.1$ & 5.20 \\
\hline Ash, $\mathrm{g} / \mathrm{kg}$ & $41.0 \mathrm{a}$ & 4.50 & $33.6-51.9$ & 10.96 & $47.9 \mathrm{a}$ & 7.25 & $32.7-62.3$ & 15.13 \\
\hline Fat, $\mathrm{g} / \mathrm{kg}$ & $251.6 a$ & 50.1 & $153.1-333.7$ & 19.91 & $201.7 \mathrm{a}$ & 40.8 & $106.5-264.0$ & 20.20 \\
\hline Protein, g/kg & 167.0a & 9.00 & $147.7-186.2$ & 5.40 & 185.3a & 21.0 & $150.6-220.9$ & 11.40 \\
\hline Energy value, $\mathrm{MJ} / \mathrm{kg}$ & $13.8 \mathrm{a}$ & 1.78 & $10.3-16.5$ & 12.93 & $12.2 \mathrm{a}$ & 1.28 & $9.29-14.3$ & 10.52 \\
\hline \multicolumn{9}{|c|}{ RTU measurement (mm) } \\
\hline SF13 & $4.98 \mathrm{aA}$ & 2.08 & $1.75-9.40$ & 41.80 & 4.83aA & 1.10 & $3.40-8.13$ & 22.82 \\
\hline SF34 & $5.17 \mathrm{aA}$ & 2.15 & $1.84-10.01$ & 41.61 & $4.97 \mathrm{aA}$ & 1.23 & $2.89-8.44$ & 24.68 \\
\hline MD13 & $19.92 \mathrm{aB}$ & 3.96 & $13.09-27.35$ & 19.88 & $29.64 \mathrm{bB}$ & 3.18 & $24.33-35.22$ & 10.73 \\
\hline MD34 & $19.71 \mathrm{aB}$ & 3.74 & $12.01-28.21$ & 18.96 & $29.17 \mathrm{bB}$ & 3.21 & $24.74-35.94$ & 11.00 \\
\hline TDtho & $12.79 a$ & 2.42 & $9.09-19.25$ & 18.89 & $12.97 a$ & 3.31 & $8.36-18.59$ & 25.52 \\
\hline
\end{tabular}

a,b: For breeds within a row, means without a common superscript are significantly different $(P<0.05)$.

A,B: For each breed and for SF and MD measurements within a column, means without a common superscript are significantly different $(P<0.05)$.

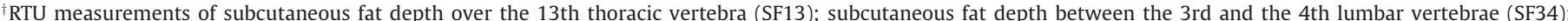

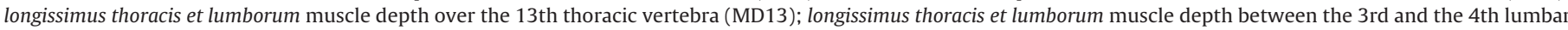
vertebrae (MD34) and tissue depth over the 11 th rib, $16 \mathrm{~cm}$ from the dorsal midline (TDtho).

Table 2

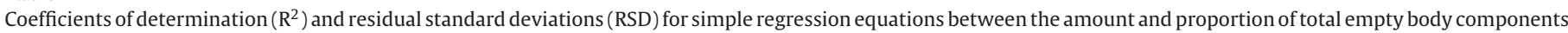
and in vivo real-time ultrasonic (RTU) measurements ${ }^{\dagger}$ for Churra da Terra Quente (CTQ) and Ile de France (IF) ewes ${ }^{\ddagger}$.

\begin{tabular}{|c|c|c|c|c|c|c|c|c|c|}
\hline \multirow[t]{3}{*}{ Whole body component } & \multirow[t]{3}{*}{ RTU measurement (mm) } & \multicolumn{4}{|c|}{ Amount } & \multicolumn{4}{|c|}{ Proportion } \\
\hline & & \multicolumn{2}{|l|}{ CTQ } & \multicolumn{2}{|l|}{ IF } & \multicolumn{2}{|l|}{ CTQ } & \multicolumn{2}{|l|}{ IF } \\
\hline & & $R^{2}$ & RSD & $R^{2}$ & RSD & $R^{2}$ & RSD & $R^{2}$ & RSD \\
\hline \multirow[t]{5}{*}{ Water } & SF13 & 0.580 & 1.900 & 0.673 & 1.730 & 0.349 & 30.8 & 0.438 & 22.6 \\
\hline & SF34 & 0.612 & 1.830 & 0.559 & 2.010 & 0.705 & 20.7 & 0.376 & 23.8 \\
\hline & MD13 & 0.827 & 1.220 & 0.620 & 1.870 & 0.802 & 17.0 & 0.519 & 20.9 \\
\hline & MD34 & 0.748 & 1.470 & 0.710 & 1.630 & 0.765 & 18.5 & 0.668 & 17.4 \\
\hline & TDtho & 0.517 & 2.040 & 0.818 & 1.290 & 0.311 & 31.7 & 0.527 & 20.8 \\
\hline \multirow[t]{5}{*}{ Fat } & SF13 & 0.908 & 1.010 & 0.768 & 1.610 & 0.783 & 23.7 & 0.751 & 20.8 \\
\hline & SF34 & 0.911 & 1.000 & 0.845 & 1.320 & 0.811 & 22.1 & 0.603 & 26.3 \\
\hline & MD13 & 0.601 & 2.110 & 0.734 & 1.730 & 0.337 & 41.4 & 0.715 & 22.3 \\
\hline & MD34 & 0.574 & 2.180 & 0.825 & 1.400 & 0.306 & 42.4 & 0.626 & 25.5 \\
\hline & TDtho & 0.851 & 1.290 & 0.842 & 1.330 & 0.722 & 26.8 & 0.718 & 22.2 \\
\hline \multirow{5}{*}{ Protein } & SF13 & 0.639 & 0.580 & 0.421 & 0.795 & 0.220 & 8.087 & 0.499 & 15.2 \\
\hline & SF34 & 0.659 & 0.564 & $0.268^{*}$ & 0.894 & 0.686 & 5.134 & 0.556 & 14.3 \\
\hline & MD13 & 0.861 & 0.360 & 0.331 & 0.855 & 0.717 & 4.875 & $0.245^{*}$ & 18.7 \\
\hline & MD34 & 0.789 & 0.444 & $0.150 \mathrm{~ns}$ & 0.964 & 0.709 & 4.935 & 0.350 & 17.3 \\
\hline & TDtho & 0.557 & 0.643 & $0.145 \mathrm{~ns}$ & 0.966 & $0.200^{*}$ & 8.191 & $0.263^{*}$ & 18.4 \\
\hline \multirow{5}{*}{$\begin{array}{l}\text { Energy } \\
\text { value }\end{array}$} & SF13 & 0.900 & 47.5 & 0.821 & 61.3 & 0.778 & 0.851 & 0.737 & 0.674 \\
\hline & SF34 & 0.906 & 46.1 & 0.852 & 55.7 & 0.809 & 0.790 & 0.613 & 0.818 \\
\hline & MD13 & 0.662 & 87.6 & 0.767 & 70.0 & 0.347 & 1.460 & 0.623 & 0.807 \\
\hline & MD34 & 0.627 & 92.0 & 0.794 & 65.7 & 0.315 & 1.495 & 0.631 & 0.798 \\
\hline & TDtho & 0.837 & 60.8 & 0.808 & 63.5 & 0.714 & 0.965 & 0.603 & 0.828 \\
\hline
\end{tabular}

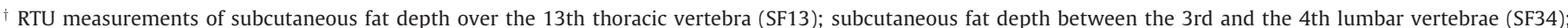

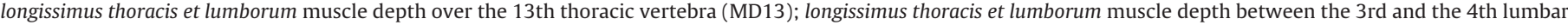
vertebrae (MD34) and tissue depth over the 11th rib, $16 \mathrm{~cm}$ from the dorsal midline (TDtho).

${ }_{\ddagger}$ All correlation coefficients are significant $(P<0.01)$ except those marked with * or with .

ns which are respectively, significant $(P<0.05)$ or not significant $(P>0.05)$.

in the total fat content and 75.1 and $60.3 \%$ of the variation in fat proportion (Table 2).

Concerning the potential of RTU measurements to estimate water and protein content in the total empty body, the results showed a lower ability to explain the variation observed than in the case of fat content and energy value (Table 2). For CTQ ewes MD13 explained the largest amount of variation in total protein content $\left(R^{2}=0.861 ; P<0.01\right)$, followed by MD34 $\left(R^{2}=0.789 ; P<0.01\right)$ and in protein proportion $\left(R^{2}=0.717 ; P<0.01\right)$, followed by MD34 $\left(R^{2}=0.709 ; P<0.01\right)$. However, for IF ewes most RTU measurements made in the present study showed to be poor estimators of protein 
Table 3

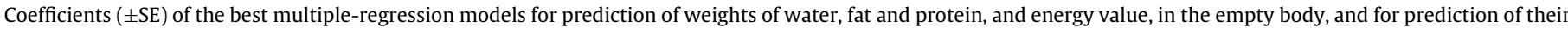
respective proportions, using live weight (LW) and in vivo real-time ultrasonic (RTU) measurements ${ }^{\dagger}$, for Churra da Terra Quente and Ile de France ewes.

\begin{tabular}{|c|c|c|c|c|c|c|c|c|c|c|}
\hline & Constant & LW & SF13 & SF34 & TDtho & MD13 & MD34 & Adjusted $R^{2}$ & RSD & $P$ \\
\hline \multicolumn{11}{|l|}{ Churra da Terra Quente } \\
\hline \multicolumn{11}{|l|}{ Empty body } \\
\hline Water (kg) & $1.81 \pm 0.838$ & $0.168 \pm 0.045$ & & & & $0.273 \pm 0.07$ & $0.176 \pm 0.07$ & 0.923 & 0.802 & 0.001 \\
\hline Fat $(\mathrm{kg})$ & $-5.13 \pm 1.22$ & $0.112 \pm 0.034$ & & $0.727 \pm 0.152$ & $0.413 \pm 0.119$ & & & 0.950 & 0.737 & 0.001 \\
\hline Protein (kg) & $0.148 \pm 0.175$ & $0.055 \pm 0.009$ & & & & $0.091 \pm 0.015$ & $0.064 \pm 0.015$ & 0.969 & 0.167 & 0.001 \\
\hline Energy value (MJ) & $-189.7 \pm 48.9$ & $7.27 \pm 1.37$ & & $29.3 \pm 6.07$ & $15.5 \pm 4.76$ & & & 0.960 & 29.5 & 0.001 \\
\hline \multicolumn{11}{|c|}{ Proportions of empty body } \\
\hline Water (g/kg) & $589.2 \pm 15.6$ & & $-19.6 \pm 2.04$ & & & $2.46 \pm 1.07$ & & 0.820 & 15.9 & 0.001 \\
\hline Fat $(\mathrm{g} / \mathrm{kg})$ & $194.7 \pm 19.1$ & & $16.8 \pm 5.37$ & $11.0 \pm 5.34$ & & $-4.22 \pm 1.34$ & & 0.851 & 19.4 & 0.001 \\
\hline Protein $(\mathrm{g} / \mathrm{kg})$ & $171.2 \pm 3.79$ & & $-2.57 \pm 1.06$ & $-2.78 \pm 1.06$ & & $1.15 \pm 0.267$ & & 0.819 & 3.83 & 0.001 \\
\hline Energy value $(\mathrm{MJ} / \mathrm{kg})$ & $11.4 \pm 0.723$ & & $0.933 \pm 0.095$ & & & $-0.116 \pm 0.05$ & & 0.827 & 0.739 & 0.001 \\
\hline \multicolumn{11}{|l|}{ Ile de France } \\
\hline \multicolumn{11}{|l|}{ Empty body } \\
\hline Water (kg) & $10.41 \pm 1.74$ & $0.299 \pm 0.028$ & & & & & & 0.834 & 1.21 & 0.001 \\
\hline Fat (kg) & $-7.51 \pm 2.233$ & & & $1.207 \pm 0.245$ & $8.36 \pm 3.42$ & & $0.271 \pm 0.122$ & 0.940 & 0.80 & 0.001 \\
\hline Protein $(k g)$ & $6.42 \pm 0.762$ & & $0.602 \pm 0.154$ & & & & & 0.394 & 0.795 & 0.008 \\
\hline $\mathrm{EV}(\mathrm{MJ})$ & $-155.3 \pm 100.5$ & & & $59.60 \pm 11.42$ & & $11.53 \pm 5.129$ & & 0.928 & 38.04 & 0.001 \\
\hline \multicolumn{11}{|c|}{ Proportions of empty body } \\
\hline Water (g/kg) & $662.9 \pm 15.49$ & & & $-19.66 \pm 3.029$ & & & & 0.652 & 17.44 & 0.001 \\
\hline Fat $(\mathrm{g} / \mathrm{kg})$ & $-43.3 \pm 41.28$ & & & $17.55 \pm 5.27$ & & & $5.406 \pm 2.016$ & 0.798 & 18.344 & 0.001 \\
\hline Protein $(\mathrm{g} / \mathrm{kg})$ & $246.8 \pm 12.35$ & & & & $-4.74 \pm 0.924$ & & & 0.535 & 14.341 & 0.001 \\
\hline $\mathrm{EV}(\mathrm{MJ} / \mathrm{kg})$ & $5.06 \pm 1.395$ & & & $0.631 \pm 0.167$ & & $0.135 \pm 0.065$ & & 0.763 & 0.625 & 0.001 \\
\hline
\end{tabular}

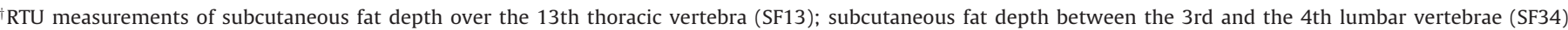

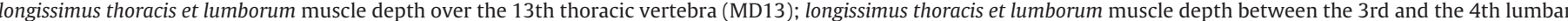
vertebrae (MD34) and tissue depth over the $11 \mathrm{th}$ rib, $16 \mathrm{~cm}$ from the dorsal midline (TDtho).

content and the best result was for SF34 as an estimator of protein proportion $\left(R^{2}=0.556 ; P<0.01\right)$.

Table 3 shows the multiple regression models that better estimated chemical body composition for CTQ and IF ewes from LW and RTU measurements. In line with the results from the simple regression analysis, the inclusion of RTU measurements in predictive models proved effective to explain most of the variation in body composition. In fact, except for the prediction of water of IF ewes, all final prediction equations for body composition components included 1-3 RTU measurements, with SF34 being the most reliable independent variable, since it was included in 9 out of the 16 equations. However, while the best models provided good estimates of fat content for both breeds $\left(R^{2} \geq 0.798 ; P<0.001\right)$ and of protein content for CTQ ewes $\left(R^{2} \geq 0.819 ; P<0.001\right)$, even the best only explain $54 \%$ of the variation in protein proportion for IF ewes.

\section{Discussion}

The absence of significant differences between the RTU measurements at the thoracic and lumbar locations within a breed is in agreement with the results of Silva et al. (2006) and Ripoll et al. (2009, 2010). Thériault et al. (2009) reported more precise measurements of fat depth between the 12th and 13th thoracic than between the 3rd and 4th lumbar vertebrae, but they explained this with the presence of a third layer of fat in the latter location, in the fattest lambs, stressing the need of a good morphological knowledge of the tissues studied-the identification of that third layer of fat would have improved the precision of the ultrasonic measurements. In fact, the layering of fat has been in the origin of erroneous estimates of subcutaneous fat but, due to the evolution in RTU images acquisition, the use of high probe frequency (i.e. $7.5 \mathrm{MHz}$ ) and image analysis, the problem raised by layering of fat will be overcome, as stated by several authors (Silva et al., 2006; Hopkins et al., 2007).
The variation in the absolute weight of fat was much better explained than the variation in fat proportion. This is in agreement with previous studies using RTU (Silva et al., 2006; Grill et al., 2015) or RTU and CT (Junkuszew and Ringdorfer, 2005), which showed more ability of measurements obtained with such technologies to estimate absolute values of different carcass or body components than to estimate the proportion of the same components. A similar pattern applies to the estimation of energy value. However, for protein estimates, there was no clear pattern concerning the estimation of absolute values versus the estimation of proportions. Whether this was largely related or not to the lower coefficients of variation observed for protein than for fat and energy value was not clear. The fact is that, as noticed by Fortin (1980), removing most of the variation of body components as proportions turn the explanation of the variation observed more difficult.

As already noticed by Silva et al. (2005), for growing lambs, the RTU measurements of subcutaneous fat in the present study explained a very large amount of the variation observed in total body fat. However, while Silva et al. (2005) showed SF13 as a better estimator of fat content than SF34, the present results tend to show SF34 as a better estimator of fat content than SF13, namely regarding absolute fat content for both breeds and in terms of fat proportion for CTQ ewes. The only exception to this trend was the amount of variation explained by fat proportion in IF ewes. The explanation of the variation in energy value followed closely the same patterns observed for fat, just tending to provide slightly less accurate estimates than for fat, especially in the case of CTQ ewes (Table 2). This could be expected given the high content of energy in fat.

The smaller amount of variation in protein content explained by RTU measurements of muscle depth when compared to the amount of variation in fat content explained by RTU measurements of fat depth was not surprising, considering that fat is the most variable tissue in mature animals. For dissectible components, Ripoll et al. (2010) noticed that, in fact, RTU muscle depth was more correlated 
with lean than fat measurements. In the same line, their results showed that RTU fat thickness was more correlated with subcutaneous fat and intermuscular fat. However, Silva et al. (2005) verified that SF13 and SF34 were the best estimators of fat and protein content respectively. The present results for chemical composition of CTQ ewes are in line with those of Ripoll et al. (2010) for dissectible components, but the results now obtained for chemical composition of IF ewes always show a RTU measurement of fat as the best estimator of protein content (SF13 for protein weight and SF34 for protein proportion). Even taking into account the differences observed in the coefficients of variation for the different body components and the various RTU measurements, between CTQ and IF ewes, there was no clear pattern that could explain breed differences concerning the relationship between ultrasonic and body components (Table 2). Still, the present results show, across the two breeds studied, the high contribution that single RTU measurements may have to explain chemical body composition, especially in terms of fat content, confirming, for mature animals, a similar conclusion is already taken by Silva et al. (2005) for growing lambs of the same breeds.

Being LW a trait easy to evaluate, it is also a trait that, in most studies of body composition, tends to account for a large amount of the variation observed in the different body components. This has been shown by several authors such as Greiner et al. (2003), in cattle, and Silva et al. (2006), and Ripoll et al. (2010), in sheep. In the present study only the best models obtained for estimation of chemical components of CTQ ewes are in agreement with those studies. Anyway, one can expect that in populations with significant variation in LW this trait can explain more variation in body composition than in a population with more homogeneous LW. On the same basis, it must be noticed that the predictive value of the models developed in the present study would probably be lower when applied to populations with lower CV for initial LW. Still, the results suggest that the inclusion of two or three RTU measurements in the model is generally enough to predict the absolute amount of the different body components and their proportions. From a practical point of view, the need for just a reduced number of RTU measurements is crucial to make the methodology applicable because the capturing of images and measurements can be speed up without impairing the precision and accuracy of predictions. This has been discussed not only for the ultrasound but other image techniques such as CT (Scholz et al., 2015).

Overall there was a clear pattern showing that absolute values of body components are estimated with higher accuracy than their proportions. For fat, this is particularly noticeable because the accuracy of the best models explained more than $94 \%$ of the body fat variation in absolute value whereas for fat proportion they only explained up to $85 \%(P<0.01)$. These values are very close to the ones obtained by Silva et al. (2005), but in the present study, the best models for estimation of fat content included one RTU measurement of muscle depth in addition to one RTU measurement of fat depth except in the case the model for fat weight in CTQ ewes.

While the results from single regression analysis for CTQ ewes had already shown that some RTU measurements can be useful for estimation of protein content. The results of multiple regression analysis show that the combination of different RTU muscle measurements (MD13 and MD34) and LW can explain 97\% $(P<0.001)$ of the variation in the absolute value of body protein. However, even the best model of protein estimation for IF ewes showed much lower accuracy, explaining only $54 \%(P<0.001)$ of the variation in protein proportion. If minor variations in protein content of mature animals are to be analyzed by RTU measurements, further studies will be necessary to confirm (or not) the potential now revealed, especially for CTQ ewes. In contrast with the results obtained by Silva et al. (2005), for lambs of both breeds considered as a whole, the best models for estimation of the protein content of CTQ ewes in the present study included, at least, one RTU measurement of muscle depth.

Teixeira (2009) pointed out that, when choosing between the different methodologies available for assessment of carcass composition, one should consider several factors such as the species concerned, the different working conditions, the accuracy of the method in making different predictions and the precision of prediction models. In reality, even using similar methodologies, factors such as the breed studied and the stage of development of the experimental animals may have an important effect on the relation established between the ultrasonic measurements taken and the body components estimated. The former situation can be illustrated by the present study and the latter by the comparison between the present results and those reported by Silva et al. (2005) with growing lambs.

\section{Conclusion}

Real-time ultrasound measurements in live ewes provided good estimates of the fat and energy content of the empty body of both breeds. They also provided good estimates of protein content for CTQ ewes, but the estimates of protein content for IF ewes were poor. The results show that predictive models that are specific to the breed and circumstances of the study in which they are to be used will have to be established to have a practical application.

\section{Conflict of interest}

None.

\section{Acknowledgement}

This work received financial support from the FCT-PEstOE/AGR/UI0772/2014 which we gratefully acknowledge.

\section{References}

AOAC, 1990. Official Methods of Analysis of the Association of Official Analytical Chemists, vol. 2., 15th ed. AOAC, Washington, DC.

Fortin, A., 1980. Fat thickness measured with three ultrasonic instruments on live ram lambs as predictors of cutability. Can. J. Anim. Sci. 60, 857-867.

Greiner, S.P., Rouse, G.H., Wilson, D.E., Cundiff, L.V., Wheeler, T.L., 2003. The relationship between ultrasound measurements and carcass fat thickness and longissimus muscle area in beef cattle. J. Anim. Sci. 81, 676-682.

Grill, L., Ringdorfer, F., Baumung, R., Fuerst-Waltl, B., 2015. Evaluation of ultrasound scanning to predict carcass composition of Austrian meat sheep. Small Rumin. Res. 123, 260-268.

Hopkins, D.L., Stanley, D.F., Ponnampalam, E.N., 2007. Relationship between real-time ultrasound and carcass measures and composition in heavy sheep. Aust. J. Exp. Agric. 47, 1304-1308.

Junkuszew, A., Ringdorfer, F., 2005. Computer tomography and ultrasound measurement as methods for the prediction of the body composition of lambs. Small Rumin. Res. 56, 121-125.

King, R.H., Speirs, E., Eckerman, P., 1986. A note on the estimation of the chemical body composition of sows. Anim. Prod. 43, 167-170.

Leymaster, K.A., Mersmann, H.J., Jenkins, T.G., 1985. Prediction of the chemical composition of sheep by use of ultrasound. J. Anim. Sci. 61, 165-172.

Mitchell, A.D., 2007. Impact of research with cattle, pigs, and sheep on nutritional concepts: body composition and growth. J. Nutr. 137, 711-714

Ripoll, G., Joy, M., Alvarez-Rodriguez, J., Sanz, A., Teixeira, A., 2009. Estimation of light lamb carcass composition by in vivo real-time ultrasonography at four anatomical locations. J. Anim. Sci. 87, 1455-1463.

Ripoll, G., Joy, M., Sanz, A., 2010. Estimation of carcass composition by ultrasound measurements in 4 anatomical locations of 3 commercial categories of lamb. J. Anim. Sci. 88, 3409-3418.

Scholz, A.M., Bünger, L., Kongsro, J., Baulain, U., Mitchell, A.D., 2015. Non-invasive methods for the determination of body and carcass composition in livestock: dual-energy X-ray absorptiometry, computed tomography, magnetic resonance imaging and ultrasound: invited review. Animal 9, 1250-1264.

Silva, S.R., Afonso, J.J., Santos, V.A., Monteiro, A., Guedes, C.M., Azevedo, J.M.T. Dias-da-Silva, A., 2006. In vivo estimation of sheep carcass composition using real-time ultrasound with two probes of 5 and $7.5 \mathrm{MHz}$ and image analysis. J. Anim. Sci. 84, 3433-3439. 
Silva, S.R., Cadavez, V.P., 2012. Real-time ultrasound (RTU) imaging methods for quality control of meats. In: Da-Wen Sun (Ed.), Computer Vision Technology in the Food and Beverage Industries. Woodhead Publishing, Cambridge, UK, pp. 277-329.

Silva, S.R., Gomes, M.J., Dias-da-Silva, A., Gil, L.F., Azevedo, J.M., 2005. Estimation in vivo of the body and carcass chemical composition of growing lambs by real-time ultrasonography. J. Anim. Sci. 83, 350-357.
Teixeira, A., 2009. Basic composition: rapid methodologies. In: Nollet, L.M.L., Toldra, F. (Eds.), Handbook of Muscle Food Analysis. CRC Press, Boston, pp. 291-314.

Thériault, M., Pomar, C., Castonguay, F., 2009. Accuracy of real-time ultrasound measurements of total tissue, fat, and muscle depths at different measuring sites in lamb. J. Anim. Sci. 87, 1801-1813.

Wright, I.A., Russel, A.J.F., 1984. Estimation in vivo of the chemical composition of the bodies of mature cows. Anim. Prod. 38, 33-44. 